\title{
Efektivitas Ankle Control Balance Training (ACBT) Terhadap Gait Ability Lansia
}

\author{
Rofi'atin ${ }^{1}$, Suryo Saputra Perdana ${ }^{1}$. \\ ${ }^{1}$ Program Studi Fisioterapi, Fakultas Ilmu Kesehatan, Universitas Muhammadiyah Surakarta \\ Jl. A. Yani Tromol Pos I Pabelan Kartasura Telp. (0271) 717417 Fax. (0271) 715448 Surakarta 57162 \\ 凶email:
}

Tanggal Submisi: 7 Januari 2020; Tanggal Penerimaan: 29 Maret 2020

\begin{abstract}
ABSTRAK
Latar Belakang: Lanjut usia atau lansia adalah seseorang yang telah memasuki usia 60 tahun. Seiring bertambah usia maka akan terjadi perubahan kualitas kesehatan lansia. Salah satu permasalahan lansia adalah jatuh. Risiko jatuh erat kaitannya dengan penurunan kondisi fisik yang berpengaruh terhadap gait ability. Risiko jatuh pada lansia dapat diturunkan dengan peningkatan gait ability. Tujuan: Penelitian ini dilakukan untuk mengetahui efektivitas ACBT terhadap peningkatan gait ability lansia.

Metode: Studi yang dipilih adalah Randomized Controlled Trial (RCT) double blinding. Teknik pengambilan sampel menggunakan purposive simple sampling. Jumlah sampel yang terpilih sebanyak 16 lansia dengan usia minimal 60 tahun, kemudian dibagi secara acak ke dalam kelompok kontrol dan intervensi. Sebelum dan setelah penelitian dilakukan tes Time Up and Go (TUG) untuk mengevaluasi gait ability. Kedua kelompok mendapat baseline treatment senam lansia dan edukasi pencegahan risiko jatuh seminggu sekali. Pada kelompok intervensi diberikan latihan tambahan berupa ACBT seminggu dua kali selama empat minggu.

Hasil: Latihan ACBT berpengaruh signifikan terhadap peningkatan gait ability lansia. Sesuai dengan uji pengaruh paired t-test yang menunjukkan $p$-value pada kelompok intervensi 0,004 $(p<0,05)$ dan t-hitung > t-tabel $(4,209>$ $2,364)$ yang artinya data berpengaruh secara signifikan. Selain itu, independent t-test menunjukkan hasil $p$-value $0,008(p<0,05)$, artinya ada perbedaan pengaruh antara kelompok intervensi dan kontrol.

Simpulan: Hasil penelitian ini menunjukkan bahwa ACBT secara statistik berpengaruh signifikan terhadap peningkatan gait ability lansia.
\end{abstract}

Kata Kunci: Ankle Control Balance Training (ACBT), gait ability, lansia, dan Time Up and Go test (TUG)

\section{ABSTRACT}

Background: Elderly is someone who has entered the age of 60 years. With the age, there will be a change in the quality of health for the elderly. One of the problems of the elderly is fall risk. The fall risk is closely related with decline in physical activity conditions that affect to gait ability. Improve gait ability can reduce the fall risk in elderly.

Purpose: This study is to know the effect of ankle control balance training on gait ability older adults.

Methods: The study uses a Randomized Controlled Trial (RCT) double blinding. The selection of samples uses purposive simple sampling. The number of selected samples was 16 elderly with $\geq 60$ years old, then randomly divided into the control and intervention groups. The Time Up and Go (TUG) test was conducted to evaluate the gait ability. Both of groups received elderly gymnastics and health education to prevent the risk of falls for once a week. The intervention group was given additional ACBT training for twice a week a months.

Results: ACBT exercises have a significant statistic effect on increasing the elderly's gait abilities. According to the paired t-test which showed in the intervention group $0.004(\mathrm{p}<0.05)$ and $\mathrm{t}$-count $>\mathrm{t}$-table $(4.209>2.364)$ which means that the result is significant. In addition, the independent t-test showed the results of $p$-value 0.008 ( $p<0.05$ ), that means there were differences affect between the intervention and control groups.

Conclusion: The results of this study indicate that ACBT has a significant statistic effect on the improvement of elderly gait ability.

Keywords: Ankle Control Balance Training (ACBT), gait ability, older adults, and Time Up and Go test (TUG) 


\section{PENDAHULUAN}

Perubahan kualitas kesehatan lansia merupakan suatu proses normal dengan terjadinya penurunan fungsi fisiologi maupun anatomi (Middleton \& Fritz, 2013). Permasalahan kesehatan yang sering terjadi pada lansia, seperti penyakit kronis, muskuloskeletal, neuromuskular, kardiopulmonal, sensory abnormalities, mental, dan kognitif (Noohu et al., 2013). Meskipun tidak disebutkan secara spesifik, jatuh menjadi permasalahan penting bagi kesehatan lansia (Moylan \& Binder, 2007; Felicia et al., 2013). Risiko jatuh erat kaitannya dengan penurunan kondisi fisik dan psikis yang berpengaruh terhadap perubahan pola jalan (Pijnappels et al., 2008; Park, 2017). Perubahan pola jalan yang terjadi, diantaranya penurunan kecepatan, panjang langkah, peningkatan fase double stance, dan lebar langkah (Shin \& An, 2014; Cruz-jimenez, 2017). Sehingga perubahan pola jalan ini akan berpengaruh terhadap penurunan kemampuan berjalan seseorang.

Perubahan dan penurunan tersebut bisa terjadi karena penurunan kekuatan otot lower limb dan lingkup gerak sendi ankle yang menyebabkan pola jalan tidak stabil (Cattagni et al., 2016). Kekuatan otot anggota gerak bawah dibutuhkan untuk mencegah jatuh (Ferreira et al., 2012; Felicia et al., 2013). Sedangkan ankle control memiliki peran penting sebagai shock absorption dan penentu momentum (Lee \& Lee, 2017). Pada ankle terdapat propioseptif memiliki peran penting memberikan informasi akan penyesuaian posisi dan pergerakan ankle terhadap anggota gerak atas sebagai balance control tubuh (Amin \& Herrington, 2014; Han et al., 2015; Bostrom et al., 2018).

Ketika kontrol postural balance tubuh terganggu dan akan terjatuh, maka otot plantar flexor memiliki peran penting untuk mengontrol pusat tubuh supaya tidak terjatuh (Pijnappels et al.,
2005). Sehingga dibutuhkan latihan untuk meningkatkan postural balance control pada ankle, salah satunya melalui Ankle Control Balance Training (ACBT) (Lee \& Lee, 2017). Berbagai jenis penelitian dan intervensi dilakukan untuk menurunkan risiko jatuh pada lansia.

Meskipun beberapa penelitian memiliki tujuan yang sama. Akan tetapi hasil penelitian menunjukkan data yang berbeda-beda. Berdasarkan berbagai perbedaan hasil penelitian yang telah dilakukan tersebut menjadikan dasar penelitian ini untuk mengetahui efektivitas ACBT terhadap gait ability lansia.

\section{METODE}

Studi yang dilakukan adalah Randomized Controlled Trial (RCT) dengan double blinding. Sampel dipilih melalui purposive simple sampling yaitu pemilihan sampel secara spesifik menggunakan kriteria inklusi dan eksklusi (Domholdt, 2000). Pelaksanaan penelitian di Panti Wredha Dharma Bhakti Surakarta yang dilaksanakan 28 Januari - 20 Februari 2019.

Jumlah sampel yang terpilih sebanyak 16 lansia yang dibagi secara acak ke dalam kelompok kontrol dan intervensi. Kedua kelompok mendapat baseline treatment senam lansia dan edukasi pencegahan jatuh seminggu sekali. Kemudian pada kelompok inervensi mendapat latihan tambahan anklecontrol balance training (ACBT) seminggu dua kali selama empat minggu. Time Up and Go Test (TUG) digunakan untuk melakukan evaluasi gait ability lansia sebelum dan sesudah pelaksanaan penelitian pada kedua kelompok.

\section{HASIL DAN PEMBAHASAN}

Setelah melakukan penelitian, penulis mendapatkan hasil yang dijelaskan dalam table di bahwah ini : 
Karakteristik Responden

Tabel 1 Distribusi usia responden

\begin{tabular}{llcc}
\hline No & $\begin{array}{l}\text { Usia } \\
\text { (tahun) }\end{array}$ & Jumlah & Persentase \\
\hline 1 & 60 & 1 & 6,3 \\
2 & 63 & 3 & 18,8 \\
3 & 65 & 1 & 6,3 \\
4 & 66 & 1 & 6,3 \\
5 & 68 & 4 & 25,0 \\
6 & 74 & 1 & 6,3 \\
7 & 76 & 1 & 6,3 \\
8 & 78 & 1 & 6,3 \\
9 & 80 & 1 & 6,3 \\
10 & 82 & 1 & 6,3 \\
11 & 83 & 1 & 6,3 \\
\multicolumn{2}{c}{ Total } & 16 & 100,0 \\
\hline \multicolumn{4}{c}{} \\
\hline
\end{tabular}

Tabel 2 Distribusi jenis kelamin responden

\begin{tabular}{lllc}
\hline No & $\begin{array}{l}\text { Jenis } \\
\text { kelamin }\end{array}$ & Jumlah & Persentase \\
\hline 1 & Perempuan & 5 & 31,3 \\
2 & Laki-laki & 11 & 68,8 \\
& Total & 16 & 100,0
\end{tabular}

Tabel 3 Distribusi MMSE responden

\begin{tabular}{llll}
\hline No & $\begin{array}{l}\text { Nilai } \\
\text { MMSE }\end{array}$ & Jumlah & Persentase \\
& 24 & 1 & 6,3 \\
2 & 25 & 3 & 18,8 \\
3 & 26 & 3 & 18,8 \\
4 & 27 & 2 & 12,5 \\
5 & 29 & 2 & 12,5 \\
6 & 30 & 5 & 31,3 \\
\multicolumn{2}{c}{ Total } & 16 & 100,0 \\
\hline
\end{tabular}

Tabel 4 Hasil statistik TUG

\begin{tabular}{lclll}
\hline & \multicolumn{2}{c}{ Intervensi } & \multicolumn{2}{c}{ Kontrol } \\
\hline & Pre-test & Post-test & Pre-test & Post Test \\
\hline Mean & 12,85 & 11,55 & 15,43 & 15,95 \\
Median & 12,50 & 11,22 & 14,85 & 15,77 \\
Minimum & 7,36 & 7,27 & 11,09 & 12,17 \\
Maksimum & 17,14 & 15,51 & 19,10 & 19,67 \\
\hline
\end{tabular}

\section{Analisa Data}

Tabel 5 Uji normalitas data

\begin{tabular}{|c|c|c|c|}
\hline \multicolumn{4}{|c|}{$p$-value } \\
\hline & ervensi & Kontrol & \\
\hline Pre-test & ,647 & ,313 & \\
\hline Post-test & 819 & 140 & \\
\hline \multicolumn{4}{|c|}{ Tabel 6 Uji pengaruh } \\
\hline Uji Pre-post test & $p$-value & t-hitung & $\mathrm{df}$ \\
\hline Intervensi &, 004 & 4,209 & 7 \\
\hline Kontrol & 281 & 1,168 & 7 \\
\hline
\end{tabular}

Tabel 7 Uji beda pengaruh

\begin{tabular}{ccc}
\hline Uji & p-value & Keterangan \\
\hline $\begin{array}{c}\text { Post-test kontrol } \\
\text { dan intervensi }\end{array}$ &, 008 & $\begin{array}{l}\text { Ada beda } \\
\text { pengaruh }\end{array}$ \\
\hline
\end{tabular}

Uji pengaruh untuk pre dan post test pada kelompok intervensi maupun kontrol menggunakan paired $t$-test yang mana nilai $\mathrm{p}<0,05$ menunjukan data berpengaruh dan t-hitung $>\mathrm{t}-$ tabel maka data berpengaruh secara signifikan (Nisfiannoor, 2009). Pada penelitian ini diperoleh nilai t-tabel 2,364. Sehingga uji data secara statistik berpengaruh signifikan. Sedangkan independent $t$-test menunjukkan adanya perbedaan pengaruh gait ability yang terjadi antara kelompok intervensi dan kontrol dengan nilai $\mathrm{p}<0,05$.

\section{Pembahasan}

Hasil penelitian menunjukkan bahwa ACBT secara statistik berpengaruh signifikan terhadap peningkatan gait ability lansia pada kelompok intervensi dibandingkan kelompok kontrol. Namun, secara clinical kurang signifikan. Hal ini dapat dievaluasi dari hasil TUG masing-masing responden pada kedua kelompok. Beberapa komponen yang dapat dievaluasi diantaranya, kondisi sampel, intervensi yang diberikan, dan outcome measurement. 
Berdasarkan kondisi sampel, banyak faktor yang berpengaruh. Jumlah sampel yang sedikit ini berpengaruh terhadap validitas hasil penelitian (Faber \& Fonseca, 2014). Selain itu, kondisi sampel dapat dievaluasi melalui data usia, kognitif, kondisi anatomi fisiologi, tingkat kesehatan, dan aktivitas sehari-hari. Semakin bertambahnya usia, maka kemampuan anatomi fisiologi menurun yang berpengaruh terhadap kualitas kesehatan sehingga kemampuan jalan juga menurun (Hanley et al., 2011; Reji \& Kaur, 2015; Sherrington \& Tiedemann, 2015; Arrieta et al., 2018; Bolding \& Corman, 2018). Namun, ada beberapa data penelitian yang tidak sesuai dengan pernyataan tersebut. Faktor lain yang dapat dievaluasi yaitu kondisi kognitif melalui Mini Mental State Examination (MMSE). Kognitif memiliki peran penting sebagai navigator terhadap berbagai perubahan dan hambatan yang terjadi ketika berjalan (Felicia et al., 2013). Selain itu, seseorang dengan aktivitas berjalan lebih banyak memiliki gait ability yang lebih baik (Pirker \& Katzenschlager, 2017).

Intervensi yang diberikan menunjukkan bahwa latihan balance control training yang dilakukan secara rutin dan terprogam dapat memperbaiki balance control yang berpengaruh terhadap peningkatan postural control melalui perubahan alignment tubuh antara center of gravity (COG) dengan base of support (BOS) (Naufal et al., 2020). Lansia yang aktif melakukan physical exercise memiliki motor ability yang baik untuk mengurangi risiko jatuh, karena kondisi fisik yang masih terjaga dengan baik sehingga postur berada dalam posisi COG dan BOS yang seimbang (Yamada et al., 2012). Meskipun, responden kelompok intervensi mendapat perlakuan sama, peningkatan hasil TUG cukup variatif dengan ratarata perbaikan minin dan rentang nilai tertinggi dan terendah cukup lebar. Hal ini dapat dipengaruhi karena respon muskuloskeletal dan neuromuskular masing-masing individu berbeda. Neuromuskular yang mengalami penurunan karena faktor usia menyebabkan respon adaptasi tubuh menjadi lambat untuk mengolah sistem informasi yang diterima dan menginterpretasikan kembali menjadi suatu gerakan (Muehlbauer et al., 2015). Sehingga kemampuan gerakan yang dilakukan antar responden pada kelompok intervensi berbeda. Misalnya, ketika diminta mengangkat kaki atau berjalan ke depan beberapa meter, responden mampu melakukannya tetapi tinggi angkatan dan langkah yang ditempuh masing-masing responden berbeda.

Pada kelompok kontrol, tidak semua responden mengalami penurunan perbaikan TUG. Hasil tersebut bisa terjadi karena outcome measurement. Bias saat melakukan pengukuran TUG yang tidak dapat dikendalikan karena pengukuran manual dan evaluasi yang hanya dilihat dari hasil kecepatan yang ditempuh. Padahal komponen pada gait ability tidak hanya kecepatan, tetapi juga irama langkah, sudut telapak kaki, panjang langkah (stride length) dan lebar langkah (stride width) (Menz et al., 2004; Shin \& An, 2014; Cruz-jimenez, 2017). Salah satu alat ukur yang dapat menjangkau komponen tersebut adalah GAITRite. GAITRite merupakan portable mat sepanjang 5 meter dengan lebar 0,9 meter memiliki 16.128 sensor (Menz et al., 2004; Wang, et al, 2015). Akan tetapi alat ini kurang praktis digunakan dan belum didistribusikan di Indonesia. Sehingga outcome measurement pada gait ability bisa menggunakan TUG yang dikombinasikan dengan 3 meter backwards walk test (3MBW) $(\mathrm{r}=0,823)$ (Carter et al., 2017). Kombinasi ini lebih baik dibandingkan dengan kombinasi lainnya.

\section{Keterbatasan Penelitian}

1)Jumlah responden yang sedikit karena kondisi kesehatan lansia yang tidak memenuhi kriteria penelitian. 
2) Memastikan setiap responden melakukan gerakan dengan standar yang sama.

3) Banyak faktor yang berpengaruh terhadap risiko jatuh pada lansia dengan penurunan kemampuan anatomi dan fisiologi yang berbeda beda pada setiap lansia.

4) Menjangkau semua faktor-faktor penyebab penurunan postural control lansia, sehingga peneliti terfokus pada perbaikan ankle control.

5) Bias yang terjadi pada pengukuran gait ability.

\section{KESIMPULAN}

Hasil penelitian menunjukan bahwa ACBT secara statistik berpengaruh signifikan terhadap peningkatan gait ability lansia pada kelompok intervensi dibandingkan kelompok kontrol. Namun, secara clinical kurang signifikan, hal ini didasarkan pada hasil peningkatan ratarata TUG yang kecil, selisih antara responden intervensi yang rentangnya lebar, dan $50 \%$ responden mengalami perbaikan TUG dengan nilai minim. Oleh karena itu, peneliti selanjutnya diharapkan dapat memperbaiki permasalahan dan keterbatasan penelitian. Lebih spesifik dan jelas dalam menentukan respoden beserta kriterianya, memilih intervensi yang sesuai dengan kondisi dan permasalahan lansia, serta menggunakan lebih dari satu outcome measurement untuk melakukan evaluasi gait ability.

\section{DAFTAR PUSTAKA}

Bolding, D. J., \& Corman, E. (2018). Falls in the Geriatric Patient Fall prevention
Older adults Risk factors Prevention. http://doi.org/10.1016/j.cger.2018.08.010

Carter, V., Jain, T., James, J., Cornwall, M., Aldrich, A., \& Heer, H. D. De. (2017). The 3-m Backwards Walk and Retrospective Falls : Diagnostic Accuracy of a Novel Clinical Measure, $1-7$.

http://doi.org/10.1519/JPT.00000000000 00149

Cattagni, T., Scaglioni, G., Laroche, D., Gremeaux, V., \& Martin, A. (2016). The Involvement of Ankle Muscles in Maintaining Balance in the Upright Posture is Higher in Elderly Fallers. EXG, 77, 38-45. http://doi.org/10.1016/j.exger.2016.02.01 0

Cruz-jimenez, M. (2017). Normal Changes in Gait and Mobility Problems in Elderly Gait Mobility Lower Extremity. Physical Medicine and Rehabilitation Clinics of NA, 28(4), 713-725. http://doi.org/10.1016/j.pmr.2017.06.005

Domholdt, E. (2000). Physical Therapy Research: Principles and Applications (2nd ed.). Philadelphia: W.B Saunders Company.

Faber, J., \& Fonseca, L. M. (2014). How sample size influences research outcomes, 19(4), 27-29.

Felicia, A., Paul, G., \& Hausdorff, J. M. (2013). Maturitas Risk factors for falls among older adults : A review of the literature. Maturitas, 75(1), 51-61. http://doi.org/10.1016/j.maturitas.2013.0 2.009

Ferreira, M. L., Sherrington, C., Smith, K., Carswell, P., Bell, R., Bell, M., ... Vardon, P. (2012). Physical Activity Improves Strength , Balance and Endurance in Adults Aged 40 - 65 years 
: a Systematic Review. Journal of Physiotherapy, 58(3), 145-156. http://doi.org/10.1016/S18369553(12)70105-4

Hanley, A., Silke, C., \& Murphy, J. (2011). Community-based health efforts for the prevention of falls in the elderly, 19-25. http://doi.org/10.2147/CIA.S9489

Lee, K., \& Lee, Y. W. (2017). Efficacy of ankle control balance training on postural balance and gait ability in communitydwelling older adults : a single-blinded, randomized clinical trial. J. Phys. Ther. Sci, 29, 1590-1595.

Menz, H. B., Latt, M. D., Tiedemann, A., Mun, M., Kwan, S., \& Lord, S. R. (2004). Reliability of the GAITRite ® walkway system for the quantification of temporo-spatial parameters of gait in young and older people, 20, 20-25. http://doi.org/10.1016/S09666362(03)00068-7

Middleton, A., \& Fritz, S. L. (2013). Assessment of Gait, Balance, and Mobility in Older Adults: Considerations for Clinicians. Current Translational Geriatrics and Experimental Gerontology Reports, 2(4), 205-214. http://doi.org/10.1007/s13670-013-00572

Moylan, K. C., \& Binder, E. F. (2007). Falls in Older Adults : Risk Assessment, Management and Prevention, 493-497. http://doi.org/10.1016/j.amjmed.2006.07. 022

Muehlbauer, T., Gollhofer, A., Lesinski, M., Hortoba, T., \& Granacher, U. (2015). Effects of Balance Training on Balance Performance in Healthy Older Adults : A Systematic Review and Meta-analysis. http://doi.org/10.1007/s40279-015-0375$\mathrm{y}$
Naufal, A. F., Khasanah, D. A. \& Noviyana, U., 2020. Hubungan Derajat Quadriceps Angle Dengan Patella Femoral Pain. FISIO MU: Physiotherapy Evidences. 1(1), pp. 29-34. http://doi.org/10.23917/j.fisiomu.v1i1.9 $\underline{504}$

Nisfiannoor, M. (2009). Pendekatan Statistik Modern. Jakarta: Salemba Humanika.

Noohu, M. M., Dey, A. B., \& Hussain, M. E. (2013). Journal of Clinical Gerontology \& Geriatrics Relevance of balance measurement tools and balance training for fall prevention in older adults. Journal of Clinical Gerontology \& Geriatics, 1-5. http://doi.org/10.1016/j.jcgg.2013.05.002

Park, J. (2017). The Effects of Eyeball Exercise on Balance Ability and Falls Efficacy of the Elderly who have Experienced a Fall : A Single-Blind, Randomized Controlled Trial. Archives of Gerontology and Geriatrics, 68, 181185.

http://doi.org/10.1016/j.archger.2016.10. 006

Pijnappels, M., Bobbert, M. F., \& Dieen, J. H. Van. (2005). Push-Off Reactions in Recovery After Tripping Discriminate Young subjects, Older Non-Fallers and Older Fallers, 21, 388-394. http://doi.org/10.1016/j.gaitpost.2004.04. 009

Pijnappels, M., Van der Burg, J. C. E., Reeves, N. D., \& Dieën, J. H. Van. (2008). Identification of Elderly Fallers by Muscle Strength Measures, 585-592. http://doi.org/10.1007/s00421-007-06136

Pirker, W., \& Katzenschlager, R. (2017). Gait disorders in adults and the elderly, 8195. http://doi.org/10.1007/s00508-0161096-4 
Sherrington, C., \& Tiedemann, A. (2015). Physiotherapy in the Prevention of Falls in Older People. Journal of Physiotherapy. http://doi.org/10.1016/j.jphys.2015.02.01 1

Shin, S.-S., \& An, D.-H. (2014). The Effect of Motor Dual-task Balance Training on Balance and Gait of Elderly Women. Journal of Physical Therapy Science, 26(3), 359-361. http://doi.org/10.1589/jpts.26.359

Wang, R., Wang, Y., \& Cheng, F. (2015). Effects of combined exercise on gait variability in community-dwelling older adults Effects of combined exercise on gait variability in community-dwelling older adults, (June). http://doi.org/10.1007/s11357-015-97802

Yamada, M., Arai, H., Sonoda, T., \& Aoyama, T. (2012). Community-Based Exercise Program is Cost-Effective by Preventing Care and Disability in Japanese Frail Older Adults. JAMDA, 13(6), 507-511. http://doi.org/10.1016/j.jamda.2012.04.0 $\underline{01}$ 